\title{
The Running Performance Decrement in Elite Hurling
}

\author{
Damien Young ${ }^{1}\left(\mathbb{D}\right.$, Jim Kilty $^{2}$, Liam Hennessy ${ }^{3}$ and Giuseppe Coratella ${ }^{4, *} \mathbb{D}$ \\ 1 Limerick Institute of Technology, Thurles Campus, Thurles, E41 PC92 Tipperary, Ireland; \\ damien.young@hotmail.com \\ 2 Premier Sports College, Blackrock, A94 F430 Dublin, Ireland; director@premiersportscollege.com \\ 3 Setanta College, Thurles, E41 AP65 Tipperary, Ireland; director@setantacollege.com \\ 4 Department of Biomedical Sciences for Health, Università degli Studi di Milano, 20133 Milano, Italy \\ * Correspondence: giuseppe.coratella@unimi.it; Tel.: +39-347-194-8321
}

Received: 9 October 2020; Accepted: 17 November 2020; Published: 19 November 2020

\begin{abstract}
Since the COVID-19 restrictions, hurling games have been played in four quarters instead of two halves. This study described the decrement in running performance between quarters in elite hurling. GPS $(10 \mathrm{~Hz})$ were used to collect data from 48 players over 20 games during 2018-2020 season. Total distance (TD), high-speed running (HSR), high-metabolic-load distance (HMLD), sprint-distance, and number of sprints (N-sprints) between quarters were assessed. Greater TD was covered in Q1 than Q3 (Cohen's $d=0.26)$. HSR and HMLD was greater in Q1 than Q2 $(d=0.45$ and $d=0.55$, respectively), Q3 ( $d=0.34$ and $d=44$, respectively) and Q4 ( $d=0.38$ and $d=0.48$, respectively). Sprint-distance and N-sprints were similar $(p>0.05)$ across quarters. All positions experienced a drop-off in at least one quarter $(d=0.43-1.46)$ in all metrics except midfielders' TD and full-forwards' HSR and HMLD. Sprint-distance and N-sprints were similar $(p>0.05)$ in each quarter for all positions. Following Q1, players were able to maintain their running performance. The current results can aid the timing of substitutions especially in positions where temporal decrements were observed.
\end{abstract}

Keywords: team sport; performance; match-play demands; high-speed running; sprint distance; quarters

\section{Introduction}

Hurling is one of the national sports played in Ireland. This stick and ball field-sport (playing area: $140 \mathrm{~m} \times 90 \mathrm{~m}$ ) is contested by two teams of 15 players (1 goalkeeper and 14 outfield players) over a duration of $70 \mathrm{~min}$. Players' technical and tactical roles differ between the five unique playing positions (full backs, half backs, midfielders, half forwards, and full forwards) [1,2]. The game is physically demanding with periods of high-intensity efforts, which are common in other team sports [2-6]. The main physical aspects of the game require players to change speed frequently. Although hurling games attract large attendances of over 80,000 people at the finals in Croke Park with several million people watching on television worldwide [7], the scientific literature has only recently described the match-play performances of competition [8-11] and training [12-14]. Players were reported to display using global positioning systems (GPS) technology, the total distance, relative distance, high-speed running (HSR), sprint distance, and high-metabolic-load distance (HMLD) were recorded in youth, sub-elite, and elite hurlers $[1,8,9,15,16]$. Quantifying the game demands is critical for the design and implementation of training practices so players can be optimally prepared for the match-play demands of competition [17].

Although the total accumulated distances can give a global indication of the match-play demands, an analysis of how these metrics change during the game could indicate the most demanding periods of play [8]. It has been shown that between-half temporal decrements in running performances exist within hurling, with total distance, high-speed running (HSR), sprint distance, and the number of sprints all shown to decrease in the second half [8]. This drop-off has been suggested to be related 
to the transient fatigue experienced throughout the game [18]. To further examine the fluctuations of running performance during the game, several team sports have further analysed the match-play running performances by smaller segments [19-22]. Dividing the match into quarters allowed coaches to identify where the temporal decrements exist [19-22]. In senior hurling, only HSR distance has been reported per quarter [2]. The results showed that HSR reduced from quarter 1 (Q1) to Q2 and from Q3 to Q4. In Gaelic football [19] and Australian football (AFL) [5], there were temporal decrements in total- and HSR-distance covered in Q2, Q3, and Q4 when compared to Q1. Unlike the unlimited substitutions permitted in AFL, only five substitutions are allowed in hurling. Knowledge of the temporal decrements per position in hurling may inform coaches of a substitution strategy, where players in the most demanding positions could be replaced. Furthermore, positional differences in the running performance between quarters have yet to be established.

Between-position running performance were recorded in hurling at U17 [23], U21 [1], and senior [8-10]. Results showed that running performance within positions decreased in the second half in hurling [1,2,9], similar to other team sports [24-26]. Currently, there are no data available that describe the total distance, HMLD, sprint distance, and the number of sprints between quarters in senior hurling. These data would help inform coaches about the fluctuations in the running performance during the game and help identify the most intense periods of the game [22]. In addition, due to COVID-19 restrictions, hurling games are now played over four quarters. Therefore, the aims of the current study were to describe the differences in running performance between quarters of match-play and within playing positions in elite senior hurling. It was hypothesized that position-specific decrements in running performances between quarters would occur as the match progresses.

\section{Materials and Methods}

\subsection{Experimental Approach to the Problem}

The current observational study was designed to examine temporal differences in match running performances between quarters of play during elite senior hurling competition. All players in the current study were competing at the highest level (Provincial and All-Ireland Senior Championship) and were selected, as they were members of the county's squad during the period that data were collected (2018, 2019, and 2020, February to September). All games took place over three seasons (2018: Championship and League: $n=7,2019$ : Championship and League: $n=9$, 2020: League: $n=4$ ) between 14.00 and $21.00 \mathrm{~h}$. Players must be have been free from injury to be included in the study. Players were divided into five playing positions: full backs, half backs, midfielders, half forwards, and full forwards. Data were only included if a full match $(70 \mathrm{~min})$ was completed. GPS was used to determine specific running performance variables. The players were requested to abstain from strenuous physical activity in the $24 \mathrm{~h}$ before competitive matches and to report to the game fully hydrated [1]. The player's hydration and dietary status were not assessed within this study.

\subsection{Subjects}

Forty-eight $(n=48)$ elite male hurlers with a mean $( \pm$ SD) age, height, and body mass of $26 \pm 6$ years, $183 \pm 3 \mathrm{~cm}$, and $88 \pm 5 \mathrm{~kg}$ respectively, volunteered to participate in the present study. Subjects had elite senior hurling training and competition experience of $8 \pm 4$ and $6 \pm 4$ years, respectively. After ethical approval, the subjects were informed of the purpose, procedures, and potential risks involved. They were also informed that they were free to withdraw from the study at any time. Written informed consent and medical declaration were obtained from the participants in line with the procedures set by the local Institution's Research Ethics Committee. The Ethics Committee in Limerick Institute of Technology approved all procedures, and the study was conducted according to the Declaration of Helsinki (1975) for studies involving human subjects. 


\subsection{Procedures}

Height and body mass without footwear and minimal clothing using a stadiometer (Seca 217, Seca Ltd., Hamburg, Germany) and Seca Weighing Scales (Seca Ltd., Hamburg, Germany) were recorded during the familiarization session. The running performances were recorded using $10 \mathrm{~Hz}$ GPS units and $100 \mathrm{~Hz}$ triaxial accelerometer (STATSports, Apex, Northern Ireland) $[1,16,27,28]$. The number of satellites was $19 \pm 7$ (n), and the horizontal dilution of precision was $1.3 \pm 0.2(\mathrm{n})$ across all games. GPS data were downloaded and further analysed by STATSports, Apex software (Firmware 2.1.15). The validity and reliability of these GPS units have been previously established [29,30]. The GPS unit (dimensions: $86 \mathrm{~mm} \times 33 \mathrm{~mm} \times 14 \mathrm{~mm}$, mass $50 \mathrm{~g}$ ) was placed within a pouch between the player's shoulder blades (upper thoracic-spine) in a sports vest and worn under the playing jersey. GPS activation and satellite lock were established 15 min before warm-up commencement [31]. The participants were familiarized with GPS technology during team training sessions before data collection [8].

Data collected from the GPS units included total distance (m), HSR $\left(17-21.9 \mathrm{~km} \cdot \mathrm{h}^{-1}\right)$, sprint distance $\left(\geq 22 \mathrm{~km} \cdot \mathrm{h}^{-1}\right)$ [1,2] and high metabolic load distance (HMLD: a metric that combines HSR distance, and distance covered while accelerating and decelerating) [9]. The total number of sprints ( $\left.\geq 22 \mathrm{~km} \cdot \mathrm{h}^{-1}\right)$ were also collected [17]. GPS data were downloaded to a computer through the STATSport analysis software (STATSport, Apex: Firmware 2.1.15) to be stored and analyzed after each game. On downloading, each GPS unit was labelled as the playing position. Quarter 1, 2, 3, and 4 data were identified by a timestamp and manually exported into a Microsoft Excel spreadsheet (Microsoft, Redmond, DC, USA).

\subsection{Statistical Analysis}

All statistical analysis was performed using SPSS for Windows (Version 22, SPSS Inc. Chicago, IL, USA). Descriptive analysis and assumptions of normality were verified before parametric statistical analysis was used. The reliability of the running performances was assessed by an intra-class coefficient (ICC). The analysis was performed using a two-way (position $\times$ quarter) mixed-model design. When an interaction occurred, a Bonferroni post hoc correction was used to detect differences between positions (five levels: full backs, half backs, midfielders, half forwards, and full forwards) and match quarters. The dependent variables across the range of analysis were total distance, HSR distance, sprint distance, HMLD and the number of sprints, with match quarters and playing positions as independent factors. Standardized effect sizes $(d)$ were calculated with $\leq 0.20$ : trivial, $0.21-0.60$ : small, $0.61-1.20$ : moderate, 1.21-2.00: large and 2.01-4.00: very large as recommended by Hopkins [32]. Statistical significance was set at an accepted level of $\alpha<0.05$. Data are presented as mean, standard deviation ( $\pm \mathrm{SD})$ and $95 \%$ confidence intervals ( $95 \% \mathrm{CI})$.

\section{Results}

The ICC was $0.755-0.903$ for total distance, $0.724-0.871$ for HSR, $0.581-0.754$ for sprint distance and $0.572-0.736$ for the number of sprints. When data are combined for the full game, players covered a total distance of $7853 \pm 1124 \mathrm{~m}$ of which $893 \pm 270 \mathrm{~m}$ and $391 \pm 131 \mathrm{~m}$ was covered at HSR- and sprint-distance speeds, respectively. The HMLD was $1607 \pm 338 \mathrm{~m}$ during the full game.

The total-, HSR-, sprint-, and HML-distances covered per quarter are presented in Figure 1. Greater total distance was covered in Q1 compared to Q3 $(d=0.26)$. The HSR- and HML-distances were greater in Q1 compared to Q2 ( $d=0.45$ and 0.55 , respectively), Q3 ( $d=0.34$ and 0.44 , respectively) and Q4 $(d=0.38$ and 0.48 , respectively). There was a similar $(p>0.05)$ sprint distance covered in each quarter. The number of sprints in Q1 (6 \pm 2$), \mathrm{Q} 2(5 \pm 2), \mathrm{Q} 3(6 \pm 2)$, and Q4 $(5 \pm 2)$ was also similar $(p>0.05)$. 

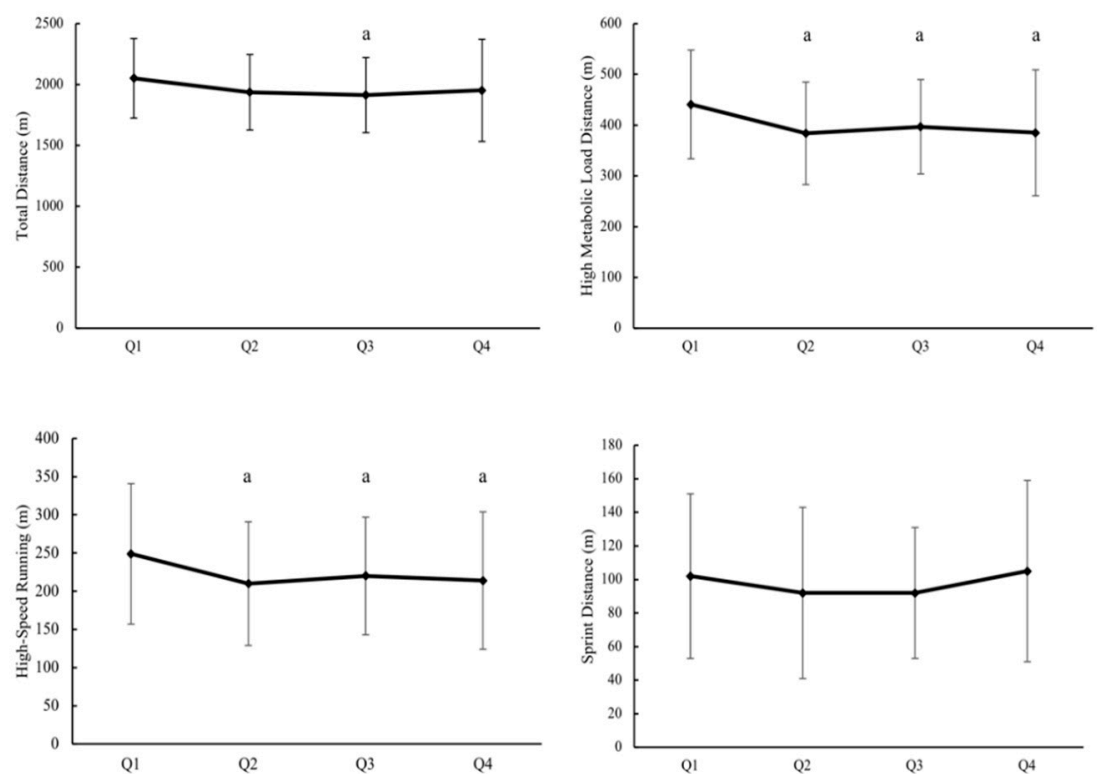

Figure 1. Mean \pm SD total-, high-speed running-, sprint- and high metabolic load-distance covered per quarter is shown. $\mathrm{Q}=$ quarter, $\mathrm{a}=$ different $(p<0.05)$ from quarter 1.

Differences between quarters within each playing position is presented in Figure 2. Full backs $(d=0.57)$, half backs $(d=0.46)$, and half forwards $(d=0.58)$ covered greater total distance in Q1 compared to Q2. Full backs $(d=0.55)$, half forwards $(d=0.81)$, and full forwards $(d=0.59)$ covered greater total distance in Q1 compared to Q3. Half forwards experienced a further reduction in total distance covered in Q4 $(d=0.96)$ compared to Q1. Full forwards covered a lower total distance in Q3 $(d=0.60)$ compared to $\mathrm{Q} 2$. There was no other difference in total distance covered between quarters in any other position $(p>0.05)$.
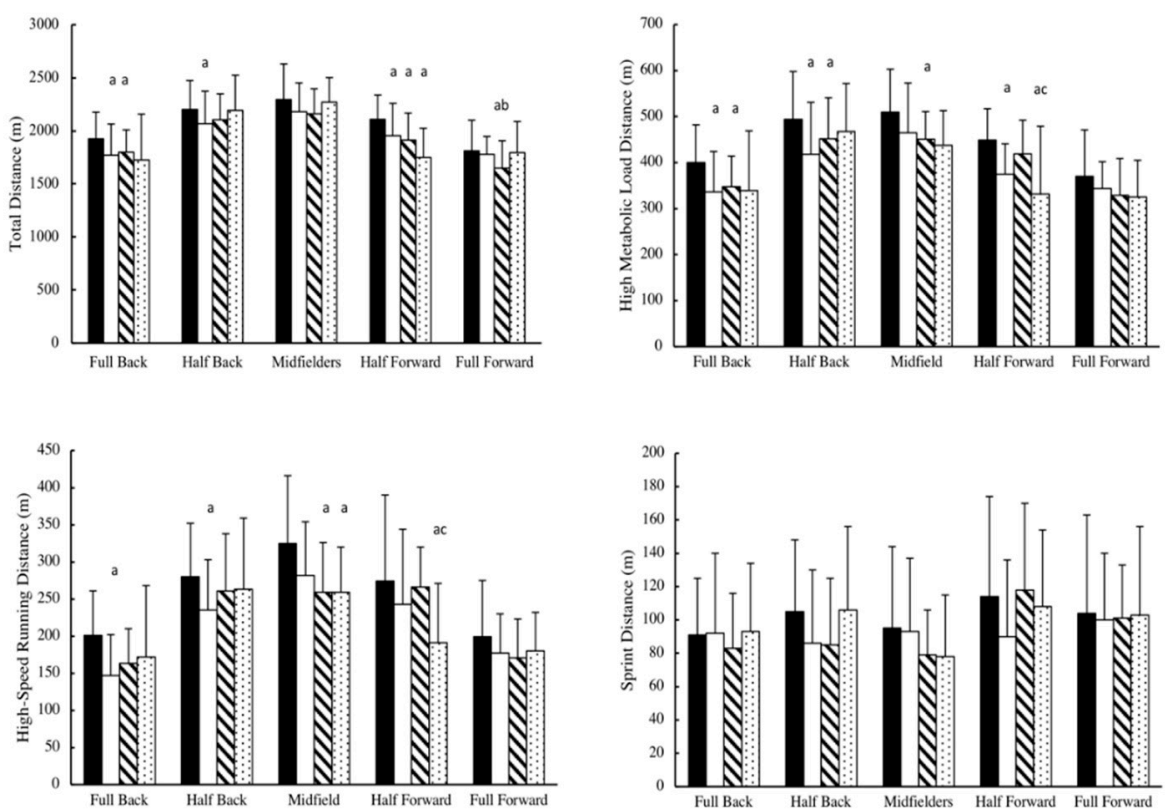

घQ1 पQ2 घQ3 घQ4

Figure 2. Mean \pm SD total-, high-speed running-, sprint-, and high metabolic load-distance covered per quarter per position is shown. $\mathrm{Q}=$ quarter, $\mathrm{a}=$ different $(p<0.05)$ from quarter $1, \mathrm{~b}=$ different $(p<0.05)$ from quarter $2, \mathrm{c}=$ different $(p<0.05)$ from quarter 3. 
There was a greater HSR distance covered by full backs $(d=0.94)$ and half backs $(d=0.64)$ in Q1 compared to Q2. Midfielders' HSR distance was greater in Q1 compared to Q3 $(d=0.83)$. Midfielders $(d=0.85)$ and half forwards $(d=0.83)$ covered a lower HSR in Q4 compared to Q1. Half forwards $(d=1.10)$ covered a lower HSR in Q4 compared to Q3. There was no other difference in HSR between quarters in any other position $(p>0.05)$. In addition, there was no temporal decrement in the total sprint distance between quarters for any position $(p>0.05)$.

Full backs $(d=0.75)$, half backs $(d=0.70)$, and half forwards $(d=1.10)$ covered greater HMLD in Q1 compared to Q2. Full backs $(d=0.70)$, half backs $(d=0.43)$, and midfielders $(d=0.75)$ and covered a lower HMLD in Q3 compared to Q1. Half forwards HMLD was lower in Q4 compared to Q1 $(d=1.02)$ and Q3 $(d=0.75)$. There was no other difference $(p>0.05)$ in HMLD between quarters.

The number of sprints performed by full backs (Q1: $6 \pm 2, \mathrm{Q} 2: 5 \pm 2, \mathrm{Q} 3: 5 \pm 1, \mathrm{Q} 4: 5 \pm 2$ ), half backs (Q1: $6 \pm 2, \mathrm{Q} 2: 5 \pm 2$, Q3: $5 \pm 3$, Q4: $5 \pm 2$ ), midfielders (Q1: $6 \pm 3$, Q2: $5 \pm 3$, Q3: $5 \pm 1$, Q4: $5 \pm 2$ ), half forwards (Q1: $6 \pm 2, \mathrm{Q} 2: 6 \pm 3, \mathrm{Q} 3: 7 \pm 2, \mathrm{Q} 4: 6 \pm 3)$, and full forwards (Q1: $6 \pm 3$, Q2: $6 \pm 2$, Q3: $6 \pm 2, \mathrm{Q} 4: 5 \pm 3$ ) showed no temporal decrements between quarters $(p>0.05)$.

\section{Discussion}

The current study aimed to describe the differences in running performance between quarters of match-play and within playing positions in elite senior hurling. The main results of the study showed that there were temporal decrements between quarters for total distance, HSR and HMLD. As hypothesized, position-specific decrements in running performances between quarters were observed in total distance, HSR, and HMLD. Interestingly, there was no difference in the total sprint distance and the number of sprints between quarters in any position. Since the current regulations due to the COVID-19 restrictions divided hurling games into quarters, the current findings will provide coaches with valuable information and practical applications.

The running performances for the full game are similar to previously reported in senior hurling [8-10,16]. Compared to the running performances covered in Q1, total distance was lower in Q3, and HSR and HMLD reduced in all quarters (Q2-Q4). Prior to this study, only HSR data were available for hurling [2]. Similar results to the current findings were shown, where players covered greater HSR ( $\left.>17 \mathrm{~km} \cdot \mathrm{h}^{-1}\right)$ in Q1 compared to Q2, Q3 and Q4 [2]. Furthermore, the total distance and HSR $\left(>17 \mathrm{~km} \cdot \mathrm{h}^{-1}\right)$ in Gaelic football decreased in all quarters (Q2-Q4) compared to Q1 [19]. Although the HSR $\left(>14.4 \mathrm{~km} \cdot \mathrm{h}^{-1}\right)$ threshold was lower in soccer than the current study $\left(17-21.9 \mathrm{~km} \cdot \mathrm{h}^{-1}\right)$, the distance covered in the last $15 \mathrm{~min}$ was shown to be $21 \%$ lower compared to the first $15 \mathrm{~min}$ [33]. Hurlers are at their freshest at the start of the game, which may allow them to cover greater distances compared to other quarters. The teams' style of play may also influence the high running performances in Q1. Some teams emphasize a high work-rate at the start of the game to create scoring chances and build a lead, and in contrast, minimize the opposition's momentum. The $15 \mathrm{~min}$ break at half-time in hurling may be satisfactory in helping players to recover and minimize the drop-off from $\mathrm{Q} 2$ to Q3. The overall match duration is $70 \mathrm{~min}$ in hurling, with the ball-in-play time shown to be $30 \mathrm{~min}$. As the duration is $20 \mathrm{~min}$ shorter than soccer, hurlers seem able to repeat the running performance in Q4 compared to Q3 without experiencing a drop-off. The current results provide coaches with the knowledge of the running performances performed in Q1 and how much the following quarters (Q2-Q4) decrease compared to Q1. Within a periodized training phase, coaches could use SSGs [34] or speed repeatability activities to replicate the total and HSR distances covered in Q1.

In the current study, the total sprint distance and the number of sprints remained consistent from quarter to quarter. These findings conflict with those observed in Gaelic football, which found that the total sprint distance decreased in each quarter (Q2-Q4) compared to Q1 [19]. The fundamental differences between how hurling and Gaelic football games are played may explain the conflicting results. The current playing style in Gaelic football sees players adopt a possession-type style of play, where teams carry the ball from defense to attack. Gaelic football teams have also set-up their defenses with additional players close to their own goals to minimize the opposition's scoring opportunities. 
Therefore, players are encouraged to hold onto possession to penetrate the defense and create a scoring opportunity [9]. In addition, players hand pass the ball to a teammate rather than kicking the ball, where they risk giving possession to the opposition. This possession-type style of play increases the volume of running as they support their teammates in possession of the football. In contrast, hurling teams adopt a more direct style of play. Players can hit the ball large distances from one end of the playing area to another with their hurley [8], which reduces the volume of running performed by hurlers. The running-type style of play where teams carry the football from defense to attack results in greater total distances and sprint distances being performed by Gaelic footballers [19] compared to hurlers $[8,9]$. This additional running in Gaelic football may explain the decrease in the sprint distance in Q2-Q4 compared to Q1. The total number of sprints is also lower in hurling compared to Gaelic football ( 43) [19]. Therefore, hurlers may repeat a smaller number of sprints without experiencing a decrease between quarters.

Previous research in hurling has shown that there were temporal decrement in second half running performance within positions [8]. This is the first study to present differences between quarters within playing positions in hurling. The current results highlight in which quarter these fluctuations occur. When the running performances were compared to Q1, full backs, half backs, and half forwards experienced a drop-off in total distance, HSR, and HMLD in Q2. The temporal decrement in HSR in full backs and half backs may give their direct opponents (half forwards and full forwards) a potential advantage to score or create scores, as they showed no difference between Q1 and Q2. Differences in tactical roles between full backs and half backs vs. half forwards and full forwards may explain the difference in HSR results. Following a shot at goal, half forwards and full forwards run out the field to set-up for the opposition puck out. This defensive action is performed quickly as the opposition goalkeeper may decide to take the puck out before they are set-up. In contrast, full backs, and half backs tactical role does not require them to retreat to their positions as quickly following a shot at goal. The current results may inform strategies around the timing of substitutions based on the position-specific decrements that occurred during the game.

Players were able to cover similar running performances in Q3 compared to Q2 in all metrics except full forwards who covered less total distance. Between $\mathrm{Q} 2$ and Q3 in hurling, a half-time period of $15 \mathrm{~min}$ takes place. Players return to the dressing room, where they usually sit-down and recover from the first half $(\mathrm{Q} 1+\mathrm{Q} 2)$. This 15 min half-time period seemed to be sufficient to allow players to maintain their performance both in Q3 and Q4. All players completed similar running performances in the final quarter compared to Q3, except for half forwards (HSR and HMLD). A change in the style of play may result in the lower running performance during the final stages of the game. If a team is losing during the last quarter, they often switch to a direct style of play, where the ball is hit over the half forwards and directly to full forwards to increase the chance of scoring a goal. In contrast, if the team is winning, the half forwards stay around the middle third to deny the space around the middle of the field. Therefore, half forwards may cover less distance in the final quarter.

The overall between-quarter positional differences in the current study conflict with those found in Gaelic football [19]. However, it is difficult to make a direct comparison, as the Gaelic football study used a broader range to describe the HSR threshold $\left(>17 \mathrm{~km} \cdot \mathrm{h}^{-1}\right.$ vs. $\left.17-21.9 \mathrm{~km} \cdot \mathrm{h}^{-1}\right)$. Nonetheless, midfielders followed by half backs and then half forwards experienced the highest decrement across quarters in HSR in Gaelic football [19]. Whereas, in the current study, the drop-off in the middle three positions was not as evident. Half backs, midfielders and half forwards in Gaelic football performed nearly double the HSR $\left(>17 \mathrm{~km} \cdot \mathrm{h}^{-1}\right)$ distance in every quarter compared to the positions in the current study. This extra distance covered in Gaelic football may have caused additional fatigue and may explain the drop-off experienced by the middle three positions compared to hurling.

In the current findings, there were no differences between quarters in any position for the total sprint distance and the number of sprints. Overall, there were $\sim 5$ sprints per quarter. Previous research in hurling has shown that the average duration between sprints was $208 \mathrm{~s}$ [10]. Players may have had enough time between sprints to maintain the number and the total sprint distance throughout 
the game. In addition, the game of hurling is continuously stopping and starting, with an average and total ball-in-play time being $\sim 22 \mathrm{~s}$ and $\sim 30 \mathrm{~min}$, respectively [15]. The players may be using the average ( $28 \mathrm{~s})$ and total ball-out-of-play time $(\sim 46 \mathrm{~min})$ [15] to recover and maintain their sprint performance for the full game. A similar sprint threshold was used in Gaelic football and the current study $\left(>22 \mathrm{~km} \cdot \mathrm{h}^{-1}\right)$. Gaelic football half backs, midfielders, and half forwards experienced greater decrements in sprint distance compared to full forwards and full backs [19]. In contrast, no positional differences were observed across any position in the current results. The middle three positions in Gaelic football tend to be involved in carrying the ball from the defense into the attack. Once a player gains possession of the ball, a number of their teammates run alongside the player to provide an option for a pass. Whereas, in hurling, once a player gains possession, they are more likely to hit the ball into the forwards. Therefore, the ball could be traveling the distance compared to the players running with the ball. This ball movement may reduce the overall volume of distance sprinted, which may minimize the drop-off between quarters observed in hurling.

The present study comes with some acknowledged limitations. Firstly, the current study only assessed the running performances between quarters of match-play. No attempt was made to include the technical or tactical elements of the game. As the ball can be hit large distances from one end of the field to the other, this may reduce the running performances during each quarter as the ball may be traveling rather than the players. Future studies should investigate the technical demands of hurling and look at how these technical skills may influence the running performances per quarter. Secondly, each quarter was divided per the total match duration. Previous research in hurling showed that the ball was only in-play for $30 \mathrm{~min}$ out of a total of $70 \mathrm{~min}$ [15]. As a result, some quarters may have more or less ball-in-play time than others. Future studies should identify the ball-in-play time and investigate the differences in running performances per quarter when the ball is in-play and out-of-play. Additionally, players were asked to present to the games fully fuelled and hydrated. No record was taken of the meals and the hydration levels of the players before the game. Future studies should assess the influence of nutrition strategies on the per quarter running performances in hurling. Lastly, it is acknowledged that GPS metrics alone do not provide a comprehensive evaluation of the training load, and further qualitative and quantitative measurements are required [35].

Some important practical applications appear considering the current findings. As several running metrics are higher in Q1 compared to other quarters, coaches need to consider the placement of their activities with the overall session design. Unconsciously, activities prescribed during the second half of training may not allow players to reach HSR speeds compared to those prescribed early in the session. This may be facilitating the drop-off in running performance in Q2, Q3, and Q4 compared to Q1. Additionally, midfielders performed a similar total distance in each quarter, but their HSR distance reduced in Q3 and Q4 compared to Q1. Conditioning for midfield players should ensure that they can cover similar HSR distances in each quarter. The distances of conditioning or hurling drills should be long enough to allow players to reach the HSR threshold. No matter what position, all players need to perform similar total sprint distances and the number of sprints. In some cases, players are divided into attackers and defenders for technical skill practice. Coaches must ensure that all players experience a sufficient volume of sprint training so they can perform the match demands.

\section{Conclusions}

The current study is the first to provide an insight into the temporal decrements in match running performances between quarters in elite hurling. The main results of the study showed that there were temporal decrements between quarters for total distance, HSR and HMLD. Quarter 1 was the most demanding with greater HSR and HMLD being performed compared to all other quarters (Q2-Q4). Position-specific decrements in running performances between quarters were observed in total distance, HSR, and HMLD. Interestingly, there was no difference in the total sprint distance and the number of sprints between quarters in any position. Since the current regulations due to the 
COVID-19 restrictions divided hurling games into quarters, the current findings will provide coaches with valuable information about the fluctuations in running performance that exist across the game.

Author Contributions: Conceptualization, D.Y.; methodology, D.Y., J.K., L.H., and G.C.; formal analysis, D.Y. and J.K.; investigation, D.Y.; resources D.Y.; data curation, D.Y. and L.H.; writing — original draft preparation, D.Y. and G.C.; writing-review and editing D.Y., J.K., L.H., and G.C.; visualization D.Y. and final approval of the version to be published D.Y., J.K., L.H., and G.C. All authors have read and agreed to the published version of the manuscript.

Funding: No external sources of funding were provided for this study.

Acknowledgments: The author would like to thank all the players, coaches and teams who participated during this research period.

Conflicts of Interest: The authors have no relevant conflict of interest to declare.

\section{References}

1. Young, D.; Mourot, L.; Beato, M.; Coratella, G. The Match Heart Rate and Running Profile of Elite Under-21 Hurlers during Competitive Match-Play. J. Strength Cond. Res. 2018, 32, 2925-2933. [CrossRef] [PubMed]

2. Collins, D.K.; McRobert, A.; Morton, J.P.; Sullivan, D.O.; Doran, D.A. The Work-Rate of Elite Hurling Match-Play. J. Strength Cond. Res. 2018, 32, 805-811. [CrossRef] [PubMed]

3. Malone, S.; Solan, B.; Hughes, B.; Collins, K. Duration specific Running performance in Elite Gaelic Football. J. Strength Cond. Res. 2017. [CrossRef] [PubMed]

4. Ryan, M.; Malone, S.; Collins, K. Acceleration Profile of Elite Gaelic Football Match Play. J. Strength Cond. Res. 2018, 32, 812-820. [CrossRef] [PubMed]

5. Coutts, A.J.; Quinn, J.; Hocking, J.; Castagna, C.; Rampinini, E. Match running performance in elite Australian Rules Football. J. Sci. Med. Sport 2010, 13, 543-548. [CrossRef]

6. Young, D.; O'Grady, M.; Coratella, G. The match-play running performance of elite Camogie players across halves of play. Sport Sci. Health 2020. [CrossRef]

7. Reilly, T.; Collins, K. Science and the Gaelic sports: Gaelic football and hurling. Eur. J. Sport Sci. 2008, 8, 231-240. [CrossRef]

8. Young, D.; Beato, M.; Mourot, L.; Coratella, G. Match-Play Temporal and Position-Specific Physical and Physiological Demands of Senior Hurlers. J. Strength Cond. Res. 2020, 34, 1759-1768. [CrossRef]

9. Young, D.; Malone, S.; Collins, K.; Mourot, L.; Beato, M.; Coratella, G. Metabolic power in hurling with respect to position and halves of match-play. PLOS ONE 2019, 14, e0225947. [CrossRef]

10. Young, D.; Coratella, G.; Malone, S.; Collins, K.; Mourot, L.; Beato, M. The match-play sprint performance of elite senior hurlers during competitive games. PLoS ONE 2019, 14, e0215156. [CrossRef]

11. Young, D.; Mourot, L.; Coratella, G. Match-play performance comparisons between elite and sub-elite hurling players. Sport Sci. Health 2018, 14, 201-208. [CrossRef]

12. Malone, S.; Collins, K.D.; Doran, D.A. The running performance and estimated energy cost of hurling specific small-sided games. Int. J. Sports Sci. Coach. 2016, 11, 853-858. [CrossRef]

13. Malone, S.; Collins, K. Effect of Game Design, Goal Type, and Player Numbers on the Physiological and Physical Demands of Hurling-Specific Small-Sided Games. J. Strength Cond. Res. 2017, 31, 1493-1499. [CrossRef] [PubMed]

14. Malone, S.; Hughes, B.; Collins, K.; Akubat, I. Methods of Monitoring Training Load and Their Association with Changes Across Fitness Measures in Hurling Players. J. Strength Cond. Res. 2020, 34, 225-234. [CrossRef]

15. Young, D.; Collins, K.; Mourot, L.; Coratella, G. The match-play activity cycles in elite U17, U21 and senior hurling competitive games. Sport Sci. Health 2019, 15, 351-359. [CrossRef]

16. Young, D.; Malone, S.; Beato, M.; Mourot, L.; Coratella, G. Identification of Maximal Running Intensities during Elite Hurling Match-Play. J. Strength Cond. Res. 2020, 34, 2608-2617. [CrossRef]

17. Wass, J.; Mernagh, D.; Pollard, B.; Stewart, P.; Fox, W.; Parmar, N.; Jones, B.; Kilduff, L.; Turner, A. A comparison of match demands using ball-in-play vs. whole match data in elite male youth soccer players. Sci. Med. Footb. 2019, 4, 142-147. [CrossRef]

18. Mohr, M.; Krustrup, P.; Bangsbo, J. Match performance of high-standard soccer players with special reference to development of fatigue. J. Sports Sci. 2003, 21, 519-528. [CrossRef] 
19. Malone, S.; Solan, B.; Collins, K. The Running Performance Profile of Elite Gaelic Football Match-Play. J. Strength Cond. Res. 2017, 31, 30-36. [CrossRef]

20. McGuinness, A.; Malone, S.; Hughes, B.; Collins, K.; Passmore, D. Physical Activity and Physiological Profiles of Elite International Female Field Hockey Players across the Quarters of Competitive Match Play. J. Strength Cond. Res. 2019, 33, 2513-2522. [CrossRef]

21. Ihsan, M.; Yeo, V.; Tan, F.; Joseph, R.; Lee, M.; Aziz, A.R. Running Demands and Activity Profile of the New Four-Quarter Match Format in Men's Field Hockey. J. Strength Cond. Res. 2018. Epub ahead of print. [CrossRef] [PubMed]

22. Lacome, M.; Piscione, J.; Hager, J.-P.; Carling, C. Fluctuations in running and skill-related performance in elite rugby union match-play. Eur. J. Sport Sci. 2016, 17, 132-143. [CrossRef] [PubMed]

23. Young, D.; Mourot, L.; Beato, M.; Coratella, G. Match-Play Demands of Elite U17 Hurlers during Competitive Matches. J. Strength Cond. Res. 2020, 34, 1982-1989. [CrossRef] [PubMed]

24. Jones, M.R.; West, D.J.; Crewther, B.; Cook, C.J.; Kilduff, L. Quantifying positional and temporal movement patterns in professional rugby union using global positioning system. Eur. J. Sport Sci. 2015, 15, 488-496. [CrossRef] [PubMed]

25. Carling, C.; Dupont, G. Are declines in physical performance associated with a reduction in skill-related performance during professional soccer match-play? J. Sports Sci. 2011, 29, 63-71. [CrossRef] [PubMed]

26. Malone, S.; Solan, B.; Collins, K.; Doran, D. The positional match running performance in elite Gaelic football. J. Strength Cond. Res. 2016, 30,1-26. [CrossRef] [PubMed]

27. Beato, M.; Coratella, G.; Schena, F.; Hulton, A.T. Evaluation of the external and internal workload in female futsal players. Biol. Sport 2017, 3, 227-231. [CrossRef]

28. Beato, M.; Impellizzeri, F.M.; Coratella, G.; Schena, F. Quantification of energy expenditure of recreational football. J. Sports Sci. 2016, 34, 1-4. [CrossRef]

29. Beato, M.; Coratella, G.; Stiff, A.; Iacono, A.D. The Validity and Between-Unit Variability of GNSS Units (STATSports Apex 10 and $18 \mathrm{~Hz}$ ) for Measuring Distance and Peak Speed in Team Sports. Front. Physiol. 2018, 9, 1288. [CrossRef]

30. Beato, M.; De Keijzer, K.L. The inter-unit and inter-model reliability of GNSS STAT Sports Apex and Viper units in measuring peak speed over 5, 10, 15, 20 and 30 meters. Biol. Sport 2019, 36, 317-321. [CrossRef]

31. Maddison, R.; Ni Mhurchu, C. Global positioning system: A new opportunity in physical activity measurement. Int. J. Behav. Nutr. Phys. Act. 2009, 6, 73. [CrossRef]

32. Hopkins, W.G. A spreadsheet for deriving a confidence interval, mechanistic inference, and clinical inference from a $p$-value. Sports Sci. 2007, 11, 16-20.

33. Bradley, P.S.; Sheldon, W.; Wooster, B.; Olsen, P.D.; Boanas, P.; Krustrup, P. High-intensity running in English FA Premier League soccer matches. J. Sports Sci. 2009, 27, 159-168. [CrossRef] [PubMed]

34. Malone, S.; Keane, J.; Owen, A.; Coratella, G.; Young, D.; Collins, K. The effect of a periodized small-sided games intervention in hurling on physical and physiological measures of performance. Sport Sci. Health 2020. Epub ahead of print.

35. Borresen, J.; Lambert, M. The Quantification of Training Load, the Training Response and the Effect on Performance. Sports Med. 2009, 39, 779-795. [CrossRef] [PubMed]

Publisher's Note: MDPI stays neutral with regard to jurisdictional claims in published maps and institutional affiliations.

(C) 2020 by the authors. Licensee MDPI, Basel, Switzerland. This article is an open access article distributed under the terms and conditions of the Creative Commons Attribution (CC BY) license (http://creativecommons.org/licenses/by/4.0/). 